\title{
EVALUATION OF THE ENERGY INTENSITY OF FORMING MACHINES COMPARED TO APPROACHES IN OTHER INDUSTRIES
}

\author{
Miroslav Běle \& Jan Hlaváč
}
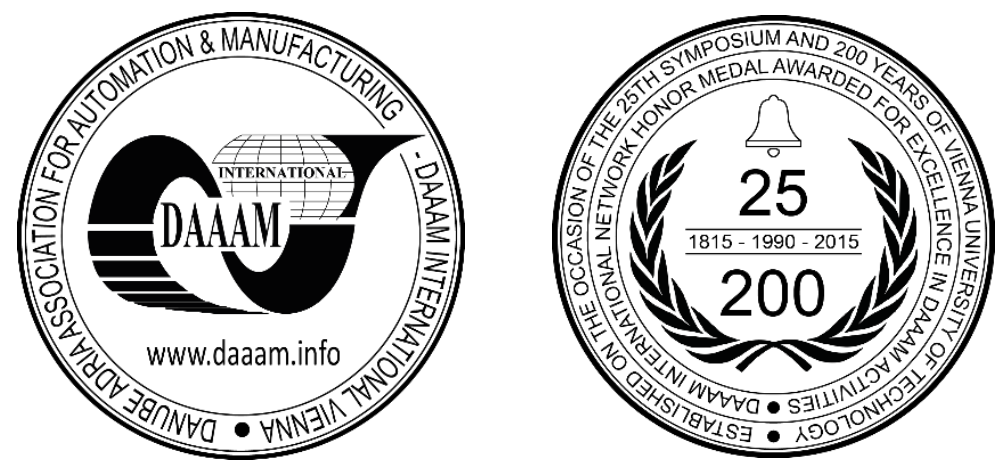

This Publication has to be referred as: Bele, M[iroslav] \& Hlavac, J[an] (2017). Evaluation of the Energy Intensity of Forming Machines Compared to Approaches in Other Industries, Proceedings of the 28th DAAAM International Symposium, pp.1057-1064, B. Katalinic (Ed.), Published by DAAAM International, ISBN 978-3-902734-11-2, ISSN 1726-9679, Vienna, Austria

DOI: $10.2507 / 28$ th.daaam.proceedings. 147

\begin{abstract}
Monitoring energy consumption of machines which are used in manufacture is a current trend. We can achieve the reduction of energy consumption by appropriate optimization. The goal of this article is to compare different approaches to energy balance in various industries. We focus on one working cycle of a forming machine, where we monitor the ratio between the used and consumed energy. We divide the consumed energy into losses caused by friction and losses due to the elastic deformation of the machine. We do not focus on energy losses during unproductive time. Different industrial sectors have different ways of dealing with energy balance we therefore decided to create a basic comparison in order to improve our existing approach to energy balance.
\end{abstract}

Keywords: Approach of energy balance; used energy; consumed energy; energy balance

\section{Introduction}

There are currently attempts in all scientific disciplines to reduce the energy demands of all products and equipment to achieve the smallest energy losses so as to minimize waste energy. These efforts not only focus on machine design and construction but also on losses during the operation of machines. Forming machines are no exception. The effort to reduce energy consumption of forming machines is very significant because there is considerable energy consumption. (For mechanical presses it is about $100 \mathrm{~kW}$, and for hydraulic presses, about $1 \mathrm{MW}$ ). One needs to find the places in a machine where the biggest energy losses are during the design of the machine. This is why it is important to focus on the way energy losses are evaluated. The principle of energy balance is used for forming machines, especially for crank presses. Different approaches to energy balance are used for different industrial products (for example [7]). The goal of this article is to map the options for energy balance assessment.

The main objective is to verify whether our approach to evaluating the energy balance of forming machines is correct and complete. We want to achieve this by using research of other approaches in other industrial branches. If we find anything useful, we will adjust our existing methodology. 


\section{Energy balance of forming machine}

Energy balance (the amount of energy which a machine must deliver to carry out its technical operation) is solved for one work cycle during continuous operation of the machine.

$$
\mathrm{A}_{\mathrm{c}}=\mathrm{A}_{\mathrm{u}} \pm \mathrm{A}_{\mathrm{d}}+\mathrm{A}_{\mathrm{z}}
$$

\section{$\mathrm{A}_{\mathrm{c}} \ldots$ Total work}

$\mathrm{A}_{\mathrm{u}} \ldots$ Useful work

$A_{d} \ldots$ Work of elastic deformations of the machine

$\mathrm{A}_{\mathrm{z}} \ldots$ Loss work of friction

Energy balance of forming machines can also be evaluated for a discontinuous work cycle. A discontinuous work cycle occurs when, after each technological operation, the crank shaft and connected ram stop in the upper dead centre of the mechanism. This means that energy is evaluated from the time when the front shaft and crank shaft of the mechanism connects with clutch until the time when the front shaft and crank shaft of the mechanism disconnects from the clutch and the crank shaft is stopped by the brake. Energy which is needed to start the machine is not considered.

\section{Example of energy balance of crank press}

Energy balance assessment of a crank press with press force $80 \mathrm{MN}$ considering these assumptions (see Table 1.). Crank press parameters:

\begin{tabular}{|l|r|l|}
\hline Stroke & 500 & $\mathrm{~mm}$ \\
\hline Rod length & 1700 & $\mathrm{~mm}$ \\
\hline Crank radius & 400 & $\mathrm{~mm}$ \\
\hline Nominal angle & 7,5 & degree \\
\hline Bearings diameter shaft/frame & 980 & $\mathrm{~mm}$ \\
\hline Bearings diameter shaft/rod & 1530 & $\mathrm{~mm}$ \\
\hline Bearings diameter rod/pin & 750 & $\mathrm{~mm}$ \\
\hline Coefficient of friction in the pins & 0,03 & \\
\hline Coefficient of friction in the ram guide & 0,05 & \\
\hline Nominal stroke & 2,45 & $\mathrm{~mm}$ \\
\hline Radius of pivot friction shaft/frame & 14,7 & $\mathrm{~mm}$ \\
\hline Radius of pivot friction shaft/rod & 22,95 & $\mathrm{~mm}$ \\
\hline Radius of pivot friction rod/pin & 11,25 & $\mathrm{~mm}$ \\
\hline
\end{tabular}

Table 1. Parameters of crank press

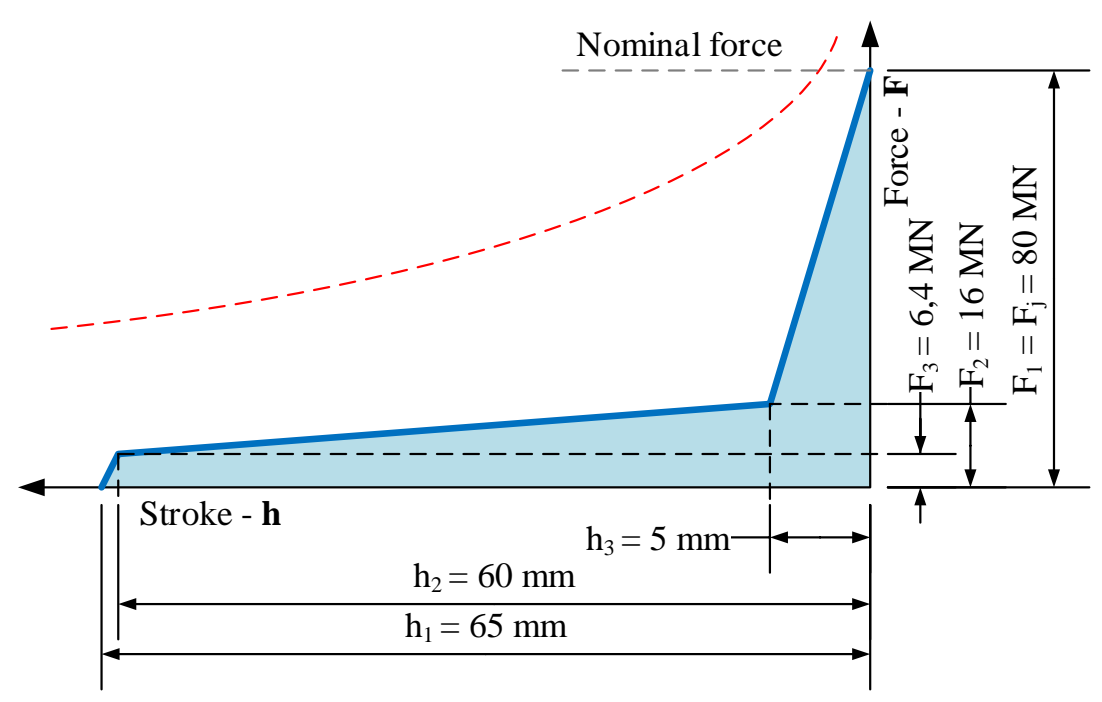

Fig. 1. Simplified graph of forming forces in relation to strokes in die forging [1] 


\section{Useful work $A_{u}$}

Useful work $A_{u}$ is work which is needed for implementation of the technical operation. For the purposes of this research, useful work size is described by an idealized course of forming characteristics (Fig. 1.).

The work is determined as the area under the curve of the shaping force. On a crank press with a nominal force $\mathrm{F}_{\mathrm{j}}=80 \mathrm{MN}$ and nominal stroke $\mathrm{h}_{\mathrm{u}}=2.45 \mathrm{~mm}, \mathrm{~A}_{\mathrm{u}}=872 \mathrm{~kJ}$.

\section{Work of elastic deformations of the machine $A_{d}$}

Work of elastic deformations of a machine $A_{d}$ is work which is accumulated into the elastic deformations of the machine caused by working force. Total deformation of the work area of the press is approx. $y=4.2 \mathrm{~mm}$, which is $A_{d}=168 \mathrm{~kJ}$. The specific distribution of the share of each component is shown in the following figure (Fig. 2.).

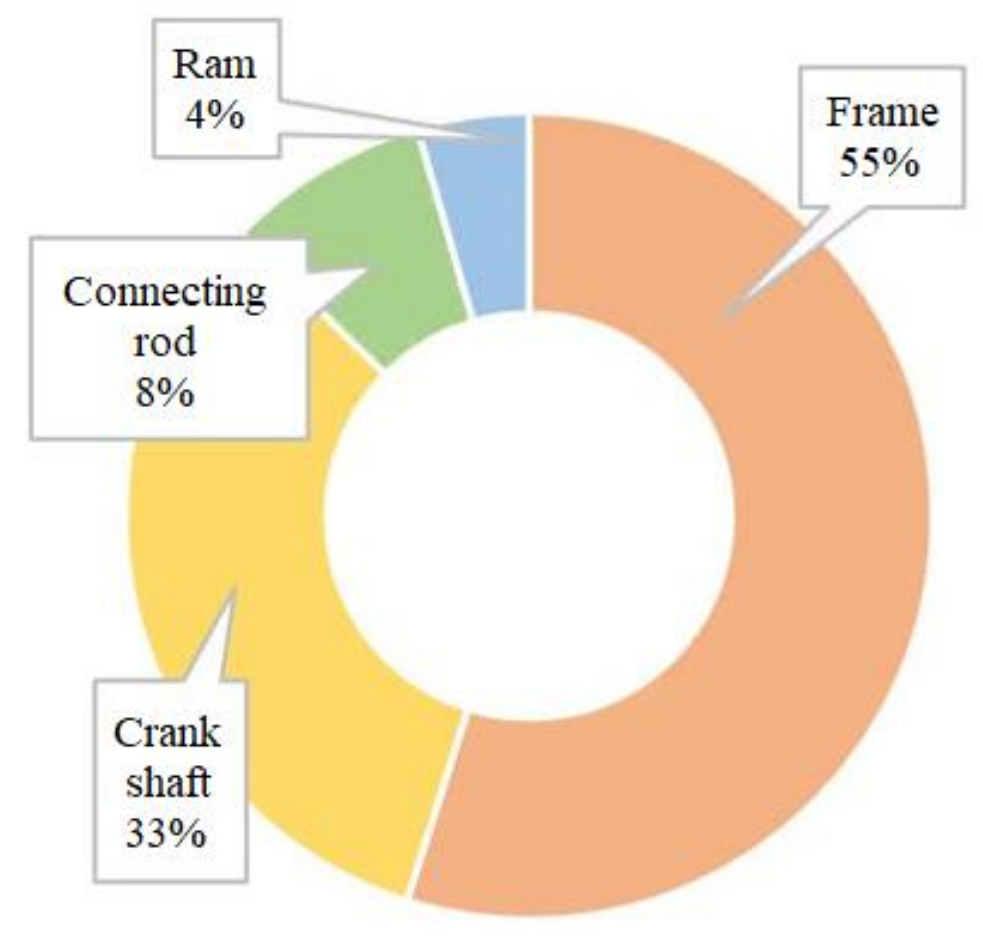

Fig. 2. Distribution of elastic deformation in press components

From the above it can be seen that when designing a machine it is necessary to focus on the frame construction, and in the drive mechanism it is necessary to focus on the parameters of the crank shaft, including the crank shaft bearing.

\section{Loss work $A_{z}$}

Loss work $A_{z}$ is work which is lost due to friction.

Coefficient of friction in the planar surface of 0.05 and in the cylindrical surface of 0.03 are considered for a specific crank press.

The following results are based on these assumptions.

$\mathrm{A}_{\mathrm{zL}}=320 \mathrm{~kJ}$

$\mathrm{A}_{\mathrm{zLe}}=500 \mathrm{~kJ}$

$\mathrm{A}_{\mathrm{zLb}}=58 \mathrm{~kJ}$

$\mathrm{A}_{\mathrm{zvb}}=3 \mathrm{~kJ}$

Total loss work is $\mathrm{A}_{\mathrm{zL}}=882 \mathrm{~kJ}$. Percentage of the share of individual works is shown in the following graph (Fig. 3.). 


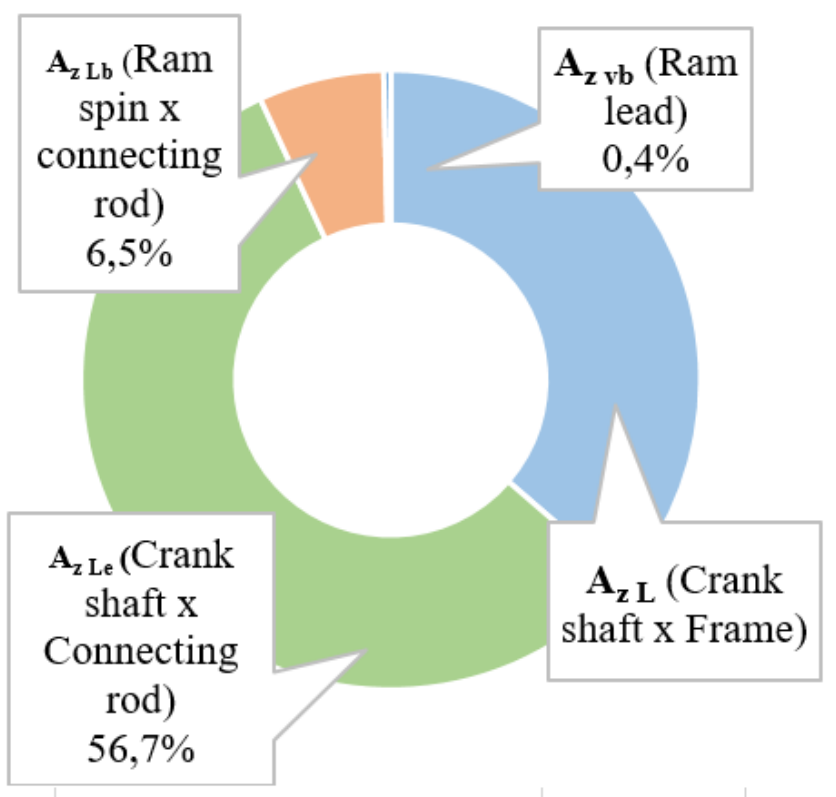

Fig. 3. Distribution of friction losses

$\mathrm{A}_{\mathrm{zL}} \ldots$ friction between the crankshaft and its placement in the rack

$\mathrm{A}_{\mathrm{zLe}} \ldots$ friction between the connecting rod and its bearing on the crankshaft

$\mathrm{A}_{\mathrm{zLb}} \ldots$ friction between the connecting rod and its mounting on the ram shaft

$\mathrm{A}_{\mathrm{zvb}} \ldots$ friction between the ram and its lead in frame

The friction losses are calculated for the position of the crank mechanism behind the lower dead centre because there is still force in the mechanism due to the machine springs. Losses in the ram are small and irrelevant in terms of the total energy balance.

As the analysis shows, the biggest energy losses are between the rod and the eccentric of the crank shaft (this can be more than $60 \%$ of the total $\mathrm{A}_{\mathrm{z}}$ of the machine). The size of this friction moment increases with increasing eccentric diameter. A significant part of the energy is lost in the place of the crankshaft mounting in the frame (up to $30 \%$ of total $\mathrm{A}_{\mathrm{z}}$ ).

\section{Evaluation of energy balance}

The way that energy balance is calculated for forming machines (crank presses) is clear. But we are interested in how energy balance and its evaluation is used in other areas, especially for other machines and equipment in industry. We want to compare and evaluate whether this approach is correct, and whether it would be possible to use it in some of the other approaches which are applied in other areas.

Distribution was created according to the time taken for the evaluation of energy balance based on extensive research from foreign and Czech sources.

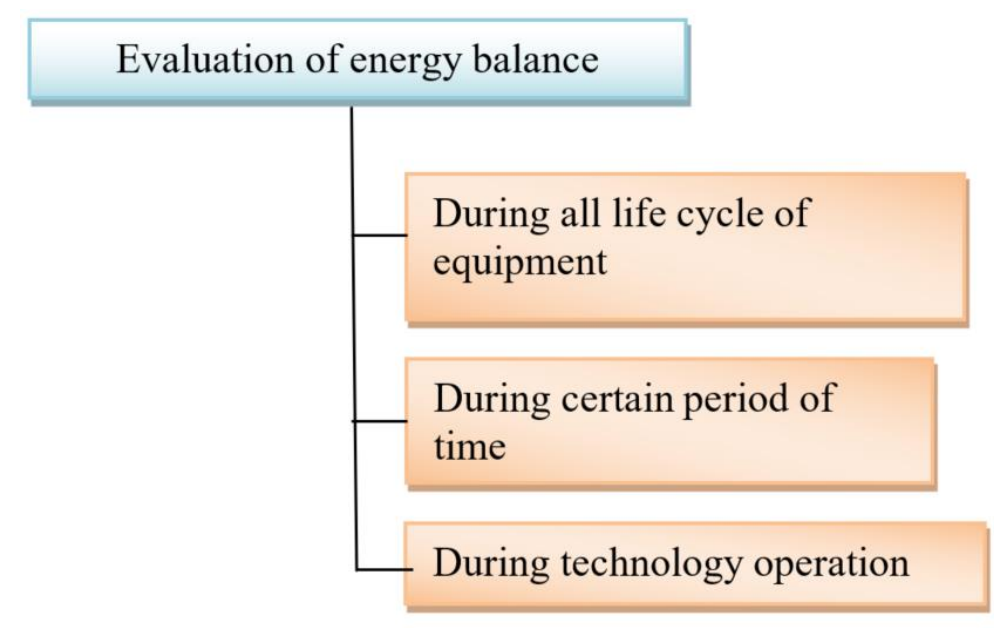


Energy balance can be evaluated:

- For the whole life cycle of the equipment: During use or during the whole life cycle. Costs are calculated for extracting raw materials and costs of liquidation in the second case.

- For a certain period of time: A certain period of time is selected for which the energy balance is evaluated.

- Or during technological operation (cutting, forming). This approach is used primarily in the field of machining technology, when energy savings of new machining technologies are evaluated.

\subsection{Energy balance during all life cycle of equipment}

The energy which is needed for the production of a machine (or equipment) is analysed. Energy for extraction of raw materials, energy for production, energy for transport to the customer, energy for lifetime use and energy for liquidation are also calculated. This is life cycle assessment (Fig. 4.).

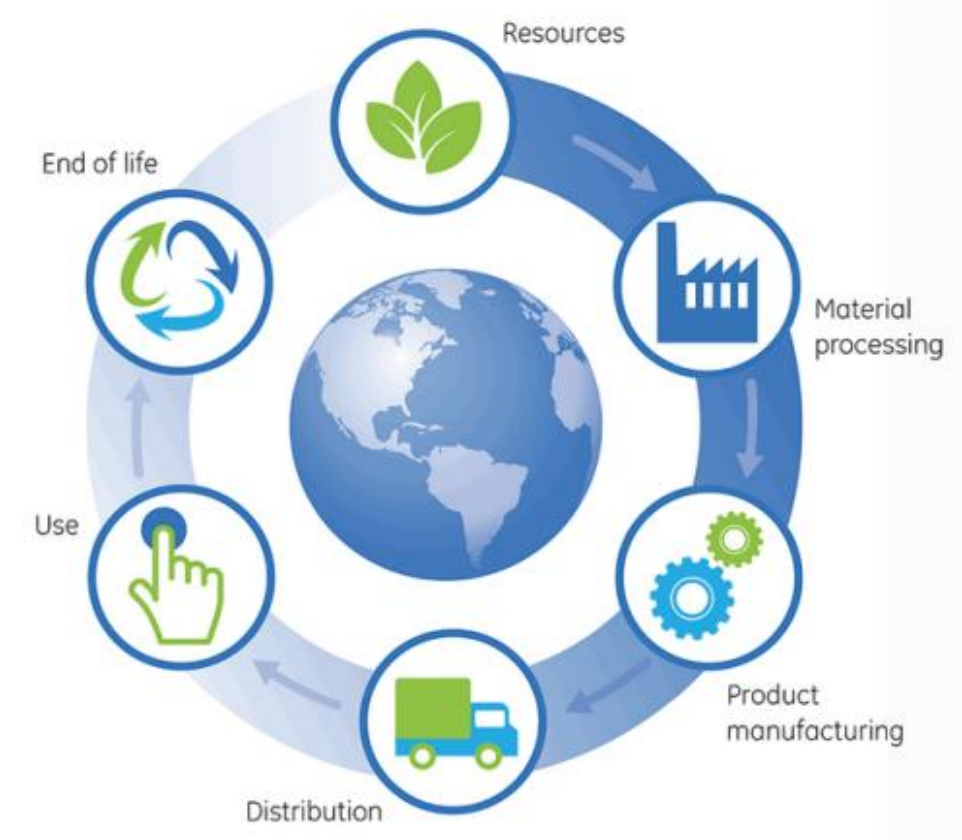

Fig. 4. Life Cycle [4]

This term is used in relation to the lifetime of equipment in some cases for example for solar panels (Fig. 5). The energy is calculated which is needed for production, and the energy which is produced by this equipment. The energy balance of the equipment for the whole lifecycle is based on these factors. This branch is marked in blue in the table. (see Table 2.)

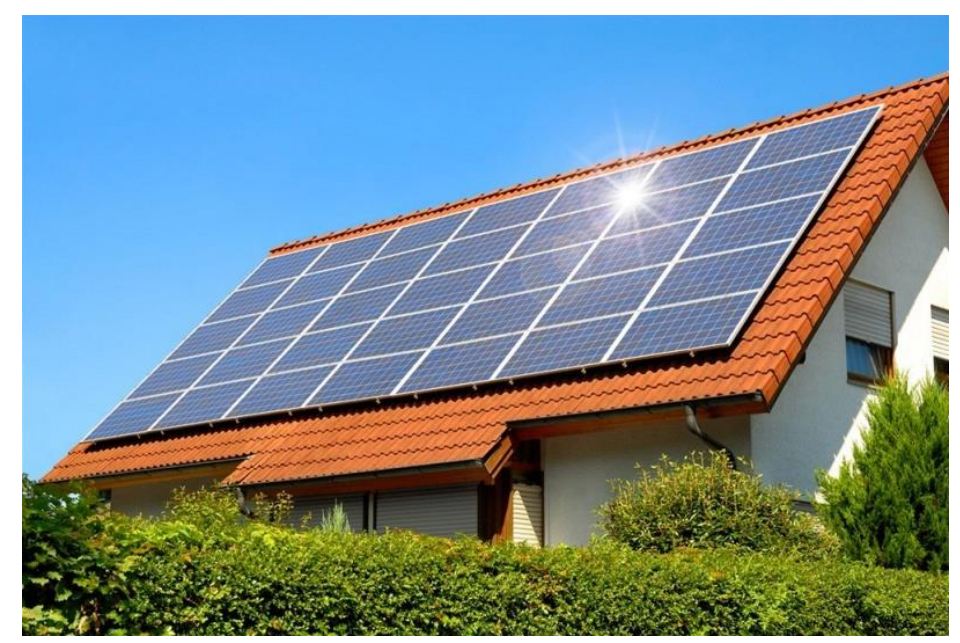

Fig. 5. Solar panels [5] 


\subsection{Energy balance during certain period of time}

The next approach is used for evaluation of machines and equipment. A time interval is considered which is described for example by one cycle of a machine or equipment (Fig. 6.). Energy balance is evaluated for this time interval. The result is the knowledge of the amount of energy which is used for a technical operation and the amount of energy which is lost by passive effects.

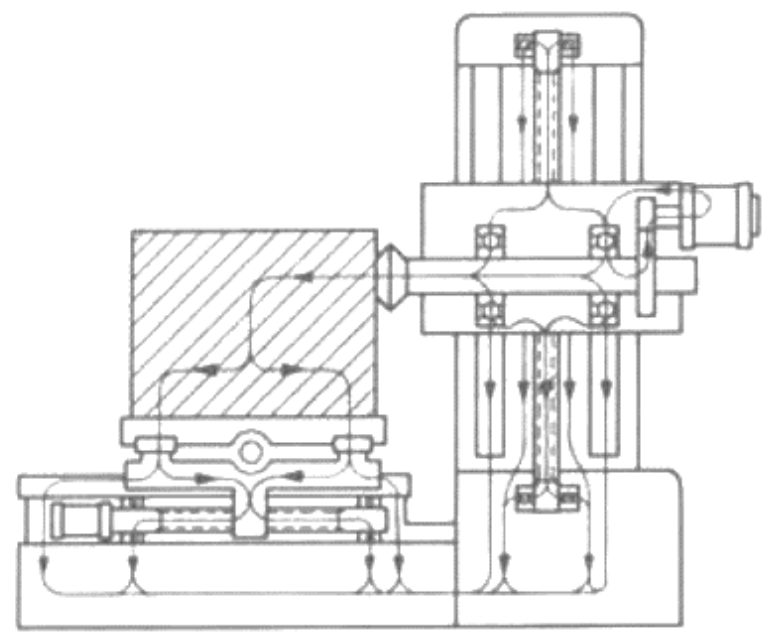

Fig. 6. Energy flow in a machine [2]

In other cases, for example in the energy balance of buildings, there is a different approach. A thermal energy source (central heating) is assumed to be installed in the building which supplies thermal energy. The amount of energy which escapes from the building is calculated. The energy class of the building is determined on the basis of the energy analysis. This approach does not evaluate the energy balance for the whole life cycle, but only for a certain period of time (Fig. 7.).

Buildings have properties which do not change over a long period of time, and therefore this approach is understood as an evaluation for the whole lifecycle. Energy which is needed for extraction of raw materials, construction and liquidation are not calculated here. This branch is marked red in the table. (see Table 2.)
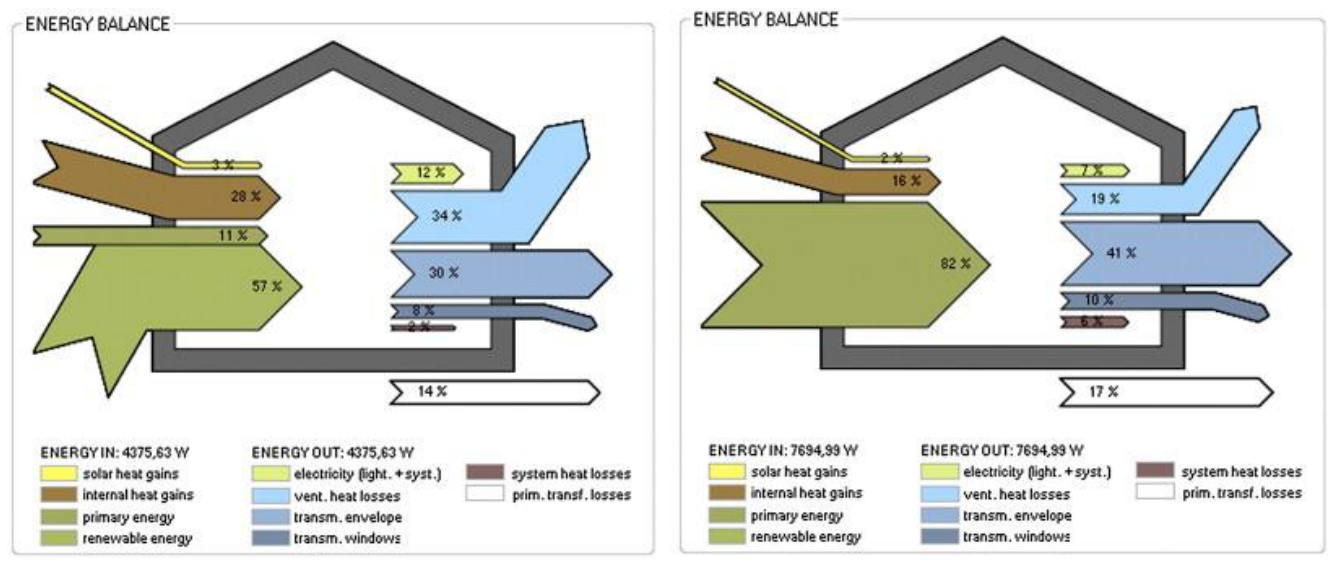

Fig. 7. Energy balance of buildings - Czech Republic [6]

\subsection{Energy balance during technology operation}

The last of approach to evaluating energy balance is used for cutting machines (for example [8]). Energy which enters the machine and energy which is used for cutting are measured. The electric motor is measured during the technological operation (milling), from which the energy for the technological operation is found. Energy which is used for cutting is measured by a dynamometer. The dynamometer is situated between the milling tool and the spindle. Cutting forces are recorded by the dynamometer during the cutting operation, from which the cutting performance and the amount of energy used for cutting is evaluated. The difference between these two energies provides information about energy balance during cutting. It describes the energy transmitted between the machine and the workpiece. This branch is marked in green in the table. (see Table 2.) 


\begin{tabular}{|c|c|c|c|}
\hline $\begin{array}{l}\text { Assessment } \\
\text { period }\end{array}$ & Branch of science & $\begin{array}{c}\text { Some cases of specific } \\
\text { use }\end{array}$ & Description \\
\hline \multirow{6}{*}{$\begin{array}{l}\text { During all } \\
\text { lifecycle of } \\
\text { equipment }\end{array}$} & \multirow{3}{*}{ Electro technics } & Solar panels & \multirow{3}{*}{$\begin{array}{l}\text { It is used to map the energy needed to } \\
\text { produce traffic and dispose of the } \\
\text { equipment. }\end{array}$} \\
\hline & & Light sources & \\
\hline & & Electric devices & \\
\hline & \multirow{3}{*}{ Energetics } & Power plants & \multirow{3}{*}{$\begin{array}{l}\text { It is used to map the energy needed to } \\
\text { produce, transport and dispose of the } \\
\text { equipment. }\end{array}$} \\
\hline & & Turbines & \\
\hline & & Boilers & \\
\hline \multirow{6}{*}{$\begin{array}{l}\text { During certain } \\
\text { period of time }\end{array}$} & \multirow[b]{2}{*}{ Construction } & Buildings & \multirow{2}{*}{$\begin{array}{l}\text { Short-term energy evaluation (eg: thermal } \\
\text { energy leakage from buildings) is used. Due } \\
\text { to the fact that the properties of the objects } \\
\text { do not change for a long time, this } \\
\text { evaluation is often valid throughout the life } \\
\text { of the object. }\end{array}$} \\
\hline & & Houses & \\
\hline & \multirow{3}{*}{ Engineering } & Machines & \multirow{3}{*}{$\begin{array}{l}\text { The energy intensity of the machine } \\
\text { (device) during the working cycle is } \\
\text { determined. This cycle is constantly } \\
\text { repeated over the service life of the } \\
\text { machine. }\end{array}$} \\
\hline & & Equipment & \\
\hline & & Production lines & \\
\hline & Electro technology & $\begin{array}{l}\text { Electric machines and } \\
\text { equipment }\end{array}$ & $\begin{array}{l}\text { The energy intensity of the machine } \\
\text { (device) during the working cycle is } \\
\text { determined. This cycle is constantly } \\
\text { repeated over the service life of the } \\
\text { machine. }\end{array}$ \\
\hline $\begin{array}{l}\text { During } \\
\text { technology } \\
\text { operation }\end{array}$ & $\begin{array}{c}\text { Machining technologies, } \\
\text { other production } \\
\text { technologies }\end{array}$ & Cutting & $\begin{array}{l}\text { Determines the energy taken by the } \\
\text { machine during a particular machining } \\
\text { operation. }\end{array}$ \\
\hline
\end{tabular}

Table 2. Summary of evaluation times of the life cycle

\section{Evaluation of achieved result and future}

The survey shows that approaches to energy balance are different in different industrial branches. Approaches range from an entirely local view of one duty cycle to an overview of the energy performance of the entire life cycle. If we want to choose the right method for describing the energy balance we must set a target against which the comparison is to be conducted.

High energy intensity is typical for forming machines because the forming process is very energy intensive. This is why we are interested in performance during forming operations. Most forming machines work in a cyclic operation, so it is appropriate to describe just one cycle. Other types of forming machines work continuously (rolling), but we did not analyse these machines.

The approach used to evaluate energy balance which is actually used here describes one work cycle of the machine and seems to be the best method.

There are other options resulting from this research. For example, to focus on the consumption of a machine out of its working cycle. For example, a flywheel spins and revolutions are maintained outside the working cycle.

In the future it would be appropriate to expand the description of energy losses to include the drive unit of a machine. A drive unit consists of a gear box, clutch, brake and also electric motor. We can achieve further energy savings by optimising these components.

\section{Conclusion}

This article summarizes the current basic and theoretical knowledge in the field of energy balance. The work describes this concept of energy balance across various scientific branches and a map shows how it is covered in other sectors. The largest part is dedicated to energy balance as it is used in the field of forming machines. Based on our research, we will expand the existing description of energy losses to include the drive unit of a machine. We did not pay attention to drive unit of machine until now.

\section{Acknowledgments}

This article was done by financial support SGS-2016-012 of University of West Bohemia. 


\section{References}

[1] Kováč, A. and Jenkut, M. (1978). Forming Machines. Bratislava: The publishing house of technical and economic literature

[2] Kamelandr, I. (1982). Forming machines I. Technical University Brno

[3] Kamelandr, I. (1982). Forming machines II. Technical University Brno

[4] BioProcess Matters life cycle, Available at: https://promo.gelifesciences.com/gl/BP/UP_art4.html, Accessed: 201709-25

[5] What Czechs, that solar panel, Available at: https://byznys.lidovky.cz/v-cr-pripada-temer-na-kazdeho-obyvatelejeden-solarni-panel-pa6-/firmy-trhy.aspx?c=A121226_160056_firmy-trhy_vs, Accessed: 2017-09-25

[6] Building information model based energy performance assessment in early design stage, Available at: http://www.sciencedirect.com/science/article/pii/S0926580508001064, Accessed: 2017-10-03

[7] Baumann, H. and Tillman, A. (2004). The Hitch Hiker's Guide to LCA. An orientation in life cycle assessment methodology and application, External organization

[8] Rief, M. and Kalhofer, E. (2017). Evaluation and modelling of the energy demand during machining. Aalen University of Applied Sciences 